\title{
Optimal waist:height ratio cut-off point for cardiometabolic risk factors in Turkish adults
}

\author{
Ahmet Selçuk Can ${ }^{1, *}$, Emine Akal Yıldız², Gülhan Samur², Neslișah Rakıcıoğlu², \\ Gülden Pekcan ${ }^{2}$, Sinan Özbayrakçı ${ }^{3}, K$ Erhan Palaoğlu ${ }^{4}$, Mithat Gönen ${ }^{5}$ and \\ Thomas P Bersot 6 \\ 'Division of Endocrinology and Metabolism, Department of Medicine, Private Gayrettepe Florence Nightingale \\ Hospital, Cemil Aslan Güder Sokak No. 8, Gayrettepe, Beșiktaș, 34349, Istanbul, Turkey: ${ }^{2}$ Division of \\ Community Nutrition, Department of Nutrition and Dietetics, Hacettepe University, Ankara, Turkey: ${ }^{3}$ Department \\ of Cardiology, Vehbi Koç Foundation American Hospital, Nişantaşı, Istanbul, Turkey: ${ }^{4}$ Department of \\ Biochemistry, Vehbi Koç Foundation American Hospital, Nişantaşı, Istanbul, Turkey: ${ }^{5}$ Department of \\ Epidemiology and Biostatistics, Memorial Sloan-Kettering Cancer Center, New York, NY, USA: ${ }^{6}$ Gladstone \\ Institute of Cardiovascular Disease and the University of California, San Francisco, CA, USA
}

Submitted 7 August 2008: Accepted 19 August 2009: First published online 28 September 2009

\begin{abstract}
Objective: To identify the optimal waist:height ratio (WHtR) cut-off point that discriminates cardiometabolic risk factors in Turkish adults.

Design: Cross-sectional study. Hypertension, dyslipidaemia, diabetes, metabolic syndrome score $\geq 2$ (presence of two or more metabolic syndrome components except for waist circumference) and at least one risk factor (diabetes, hypertension or dyslipidaemia) were categorical outcome variables. Receiver-operating characteristic (ROC) curves were prepared by plotting $1-$ specificity on the $x$-axis and sensitivity on the $y$-axis. The WHtR value that had the highest Youden index was selected as the optimal cut-off point for each cardiometabolic risk factor (Youden index $=$ sensitivity + specificity -1 ).

Setting: Turkey, 2003.

Subjects: Adults (1121 women and 571 men) aged 18 years and over were examined.

Results: Analysis of ROC coordinate tables showed that the optimal cut-off value ranged between 0.55 and 0.60 and was almost equal between men and women. The sensitivities of the identified cut-offs were between 0.63 and 0.81 , the specificities were between 0.42 and 0.71 and the accuracies were between 0.65 and 0.73 , for men and women. The cut-off point of 0.59 was the most frequently identified value for discrimination of the studied cardiometabolic risk factors. Subjects classified as having WHtR $\geq 0.59$ had significantly higher age and sociodemographic multivariable-adjusted odds ratios for cardiometabolic risk factors than subjects with WHtR $<0.59$, except for diabetes in men.

Conclusions: We show that the optimal WHtR cut-off point to discriminate cardiometabolic risk factors is 0.59 in Turkish adults.
\end{abstract}

\author{
Keywords \\ Waist:height ratio \\ Anthropometry \\ Cardiometabolic risk factors
}

From a public health perspective, identification of the best anthropometric discriminator of cardiometabolic risk factors would provide a simple, cheap and useful tool. Measurement of waist circumference (WC) is recommended by the US National Cholesterol Education Program (NCEP) Adult Treatment Panel III (ATP III) to diagnose the metabolic syndrome and to assess central obesity $^{(1)}$. The metabolic syndrome is important, because it is associated with a threefold increase in CVD risk, a fivefold increased risk of diabetes mellitus (DM) and a twofold increase in all-cause mortality ${ }^{(2-5)}$. Based on data from a large prospective study with 10 years of follow-up of 359387 subjects, Pischon et al. recommended using WC or waist:hip ratio (WHpR) in addition to BMI in assessing future risk of mortality ${ }^{(6)}$. Global acceptance of WC as the best anthropometric index would imply that a $186 \mathrm{~cm}$ tall man with a WC of $117 \mathrm{~cm}$ has the same cardiometabolic risk as a $168 \mathrm{~cm}$ tall man with a WC of $117 \mathrm{~cm}$, considering all classical cardiovascular risk factors like age, smoking habit, blood pressure and lipids are equal. In contrast, it has been shown that height has an inverse association with CVD and total mortality ${ }^{(7-9)}$. In a recent meta-analysis, Lee and co-workers found that central obesity markers, especially waist:height ratio 
(WHtR), are superior to BMI for predicting cardiovascular risk factors (hypertension, type $2 \mathrm{DM}$ and/or dyslipidaemia) in both men and women ${ }^{(10)}$. Other investigators have also proposed the use of WHtR to predict CVD risk and metabolic syndrome ${ }^{(11-18)}$. In a previous issue of this journal, we reported that WHtR is the best anthropometric index in Turkish adults ${ }^{(19)}$. To enable this information to be practical and helpful, we now aim to identify the optimal WHtR cut-off point for discrimination of cardiometabolic risk factors in Turkish men and women.

\section{Methods}

The current report is a continuation of our previous publication $^{(19)}$. Information about subject characteristics, informed consent, compliance with the Helsinki Declaration, laboratory methods, definitions of cardiovascular risk factors and limitations of the study can be found in our earlier paper ${ }^{(19)}$. The Central Ethics Committee of the Turkish Ministry of Health approved the study and granted permission for its conduct. There were 571 men and 1121 women in this cross-sectional epidemiological survey that was performed in 2003. Subjects who were more than 17 years old were recruited from neighbourhood groups and with local advertisements in Istanbul, an urban area and in villages of Kayseri, a rural area. The survey was not nationally representative. Information on education, income, past medical history, smoking, alcohol consumption and physical activity was collected through faceto-face physician interview. Monthly family income was categorized as $<125 €, 125-250 €, 250-500 €$ and $>500 €$. Subjects were classified as low education level if they were illiterate, literate only or had $\leq 5$ years of elementary school education. Subjects who had $>5$ years of education were classified as high education level. Physical activity was categorized as $>4 \mathrm{~h}, 1-4 \mathrm{~h},<1 \mathrm{~h}$ and no physical activity per week and was based on self-report. Subjects who consumed at least one alcoholic beverage per month were assigned into the drinker category. Smoking was categorized as ex-, never and current smoker status.

Height was measured to within $0.5 \mathrm{~cm}$ with a measuring stick, weight to within $0 \cdot 1 \mathrm{~kg}$ with a digital scale, WC and hip circumference (HC) to the nearest $0.5 \mathrm{~cm}$ with a non-elastic measuring tape. WC was measured at the midpoint between the last rib and the superior iliac crest during mild expiration. HC was measured at the level of the greater trochanter. All measurements were taken when subjects wore light clothing and after shoes were taken off. BMI was calculated as weight in kilograms divided by the square of height in metres $\left(\mathrm{kg} / \mathrm{m}^{2}\right)$. Blood pressure (BP) was measured on the right arm with an automated sphygmomanometer (Omron automatic blood pressure monitor with IntelliSense ${ }^{\circledR}$, Bannockburn, IL, USA) after $15 \mathrm{~min}$ of rest with the subject in the sitting position. A $10 \mathrm{~h}$ fasting blood sample was obtained from the subjects. Total cholesterol (TC), HDL cholesterol (HDL-C), LDL cholesterol (LDL-C), TAG, glucose and insulin levels were measured with standard commercial methods ${ }^{(19)}$. Insulin resistance was estimated with the homeostasis model assessment insulin resistance index (HOMA-IR), calculated from the equation $^{(20)}$ : HOMA-IR $=$ [fasting serum insulin $(\mu \mathrm{U} / \mathrm{ml}) \times$ fasting plasma glucose $(\mathrm{mmol} / \mathrm{l})] / 22 \cdot 5$.

\section{Definitions of cardiometabolic risk factors}

Hypertension was defined as systolic $\mathrm{BP} \geq 140 \mathrm{mmHg}$, diastolic $\mathrm{BP} \geq 90 \mathrm{mmHg}$ or concurrent use of antihypertensive medications ${ }^{(21)}$. In accordance with the NCEP ATP III criteria, dyslipidaemia was defined if any of the following was present: serum TC $\geq 240 \mathrm{mg} / \mathrm{dl}$, HDL$\mathrm{C}<40 \mathrm{mg} / \mathrm{dl}$, LDL-C $\geq 160 \mathrm{mg} / \mathrm{dl}$ or serum TAG $\geq 200$ $\mathrm{mg} / \mathrm{dl}^{(1)}$. DM was diagnosed either from concurrent use of antidiabetic medications or if fasting plasma glucose was $\geq 126 \mathrm{mg} / \mathrm{dl}^{(22)}$. The cut-off points for abnormal metabolic syndrome components are illustrated in Table 1. Metabolic syndrome was diagnosed if three or more abnormal modified NCEP ATP III criteria were present $^{(1,23)}$. If a subject had two or more abnormal metabolic syndrome components, except for the WC component, he or she was categorized into the metabolic syndrome score $\geq 2$ (MSS $\geq 2$ ) group. MSS $\geq 2$ was a state variable in receiver-operating characteristic (ROC) curve analysis and a dependent variable in logistic regression analysis. Inclusion of WC in the MSS $\geq 2$ category would cause multicollinearity between the independent variable (WHtR) and the dependent variable (metabolic syndrome); therefore it was appropriate to exclude WC from the definition of the metabolic syndrome. If subjects had hypertension or dyslipidaemia or diabetes, they were categorized into at least one risk factor (ALORF) positive

Table 1 Cut-off points for abnormal metabolic syndrome components

\begin{tabular}{lll}
\hline Component & \multicolumn{1}{c}{ Cut-off point for men } & \multicolumn{1}{c}{ Cut-off point for women } \\
\hline WC & $\geq 102 \mathrm{~cm}$ & $\geq 88 \mathrm{~cm}$ \\
Blood pressuret & SBP $\geq 130$ or DBP $\geq 85 \mathrm{mmHg}$ & SBP $\geq 130$ or DBP $\geq 85 \mathrm{mmHg}$ \\
TAGt & $\geq 150 \mathrm{mg} / \mathrm{dl}(\geq 1.69 \mathrm{mmol} / \mathrm{l})$ & $\geq 150 \mathrm{mg} / \mathrm{dl}(\geq 1 \cdot 69 \mathrm{mmol} / \mathrm{l})$ \\
HDL-Ct & $<40 \mathrm{mg} / \mathrm{dl}(<1.03 \mathrm{mmol} / \mathrm{l})$ & $<50 \mathrm{mg} / \mathrm{dll}(<1 \cdot 29 \mathrm{mmol} / \mathrm{l})$ \\
Glucoset & $\geq 100 \mathrm{mg} / \mathrm{dl}(\geq 5.56 \mathrm{mmol} / \mathrm{l})$ & $\geq 100 \mathrm{mg} / \mathrm{dl}(\geq 5 \cdot 56 \mathrm{mmol} / \mathrm{l})$ \\
\hline
\end{tabular}

WC, waist circumference; HDL-C, HDL cholesterol; SBP, systolic blood pressure; DBP, diastolic blood pressure.

Metabolic syndrome is diagnosed if an individual has three or more abnormal components according to modified US National Cholesterol Education Program Adult Treatment Panel III criteria ${ }^{(1,23)}$.

tff a subject is on drug therapy for the component, he or she is assigned to an abnormal component status. 
status. ALORF and MSS $\geq 2$ were categorical variables with a binary (yes/no) outcome like hypertension, diabetes and dyslipidaemia, the other dependent variables.

\section{Statistical methods}

The SPSS statistical software package version $15 \cdot 0$ (SPSS Inc., Chicago, IL, USA) was used for statistical analyses. Continuous variables with a normal distribution are presented as means and standard deviations. Continuous variables with a positively skewed distribution are presented as median, 25th and 75th percentiles. Categorical variables are presented as percentage and $95 \%$ confidence interval. ROC curves were prepared by plotting $1-$ specificity on the $x$ axis and sensitivity on the $y$-axis. WHtR was rounded to two decimals in ROC analyses. The difference between area under the curve (AUC) of WHtR for each cardiometabolic risk factor and the value of 0.50 , the area under the line of no discrimination, was compared ${ }^{(24)}$. The optimal WHtR cut-off was found by calculating the Youden index, $J^{(25)}$ : $J=$ sensitivity + specificity -1 . The WHtR value that had the highest $J$ was selected as the best cut-off point for each cardiometabolic risk factor. We identified the cut-offs using the Youden index for the reasons delineated by Perkins and Schisterman ${ }^{(26)}$. Cut-offs estimated from the alternative method, closest to the coordinate of sensitivity $=1$ and $1-$ specificity $=1$ in ROC curve analysis (closest to the ideal marker), were within -0.04 to +0.05 of the cut-offs estimated by $J$. Cut-offs identified by $J$ and closest to the ideal marker were the same $50 \%$ of the time when ROC curves were constructed separately for each gender. Cut-offs identified by $J$ and closest to the ideal marker were the same $60 \%$ of the time when ROC curves were constructed separately for each gender and age tertile. As per Perkins and Schisterman ${ }^{(26)}$ the point on the ROC curve closest to the ideal marker attempts to find the cut-off point that discriminates the presence of the condition from the absence of the condition perfectly, but involves a quadratic term with unknown clinical meaning. $J$ is the maximum vertical distance on the curve from the line of no discrimination and reflects the discriminatory capability furthest from chance ${ }^{(26)}$. J attempts to maximize correct classification and minimize incorrect classification ${ }^{(26)}$. The most frequently occurring cut-off was arbitrarily selected as optimal in order to conclude a single cut-off instead of multiple optimal cutoff points for various cardiometabolic risk factors.

The sensitivities and specificities were obtained from the coordinate tables of ROC curves. The following formulas were used in calculating the positive predictive value (PPV), negative predictive value (NPV) and accuracy of the identified cut-offs ${ }^{(27)}$ :

$$
\begin{aligned}
\mathrm{PPV}= & \text { prevalence } \times \text { sensitivity } /[\text { prevalence } \times \text { sensitivity } \\
& +(1-\text { prevalence }) \times(1-\text { specificity })] \\
\mathrm{NPV}= & {[(1-\text { prevalence }) \times \text { specificity }] /[(1-\text { prevalence })} \\
& \times \text { specificity }+ \text { prevalence } \times(1-\text { sensitivity })]
\end{aligned}
$$

and

$$
\begin{aligned}
\text { Accuracy }= & 1-[\text { prevalence } \times(1-\text { sensitivity }) \\
& +(1-\text { prevalence }) \times(1-\text { specificity })] .
\end{aligned}
$$

Subjects were classified as under $v$. at or above the optimal WHtR cut-off point, creating a categorical variable with a binary outcome. A multivariable logistic regression model was used to test the predictive ability of the cut-off identified in discriminatory ROC curve analysis. The model included age, rural $v$. urban residence, smoking, alcohol consumption, physical activity, income, education level and WHtR category as independent variables and hypertension, dyslipidaemia, diabetes, MSS $\geq 2$ and ALORF as dependent variables. Adjusted odds ratios of cardiometabolic risk factors for being at or above the optimal WHtR cut-off $v$. being below the optimal WHtR cut-off were calculated.

\section{Results}

Clinical characteristics of the study sample are presented in Tables 2 and 3. The age range of women was between 18 and 90 years. The age range of men was between 19 and 80 years. ROC curves were constructed to measure the degree of discrimination of WHtR for hypertension, dyslipidaemia, diabetes, MSS $\geq 2$ and ALORF. The AUC of WHtR for cardiometabolic risk factors are presented in Table 4 and are significantly different from the AUC value

\begin{tabular}{|c|c|c|c|c|}
\hline \multirow[b]{2}{*}{ Characteristic } & \multicolumn{2}{|c|}{ Men ( $n$ 571) } & \multicolumn{2}{|c|}{ Women (n 1121) } \\
\hline & Mean & SD & Mean & SD \\
\hline Age (years) & 45 & 13 & 46 & 13 \\
\hline Height $(\mathrm{cm})$ & $170 \cdot 7$ & $7 \cdot 3$ & $155 \cdot 7$ & $6 \cdot 7$ \\
\hline Weight (kg) & $82 \cdot 6$ & $12 \cdot 8$ & $73 \cdot 1$ & $13 \cdot 4$ \\
\hline BMI $\left(\mathrm{kg} / \mathrm{m}^{2}\right)$ & $28 \cdot 3$ & $3 \cdot 7$ & $30 \cdot 2$ & $5 \cdot 4$ \\
\hline WC (cm) & $99 \cdot 6$ & $10 \cdot 3$ & $92 \cdot 7$ & $12 \cdot 6$ \\
\hline WHpR & 0.92 & 0.06 & 0.83 & 0.08 \\
\hline WHtR & 0.58 & 0.06 & $0 \cdot 60$ & 0.09 \\
\hline SBP $(\mathrm{mmHg})$ & 133 & 20 & 135 & 26 \\
\hline DBP $(\mathrm{mmHg})$ & 85 & 12 & 86 & 13 \\
\hline Glucose $(\mathrm{mmol} / \mathrm{l})$ & $5 \cdot 49$ & $1 \cdot 74$ & $5 \cdot 28$ & $1 \cdot 74$ \\
\hline Insulin (pmol/l)† & $53 \cdot 1$ & $36 \cdot 1,78 \cdot 8$ & $52 \cdot 4$ & $36 \cdot 2,73 \cdot 5$ \\
\hline HOMA-IRt & $1 \cdot 74$ & $1 \cdot 14,2 \cdot 67$ & $1 \cdot 58$ & $1 \cdot 08,2 \cdot 47$ \\
\hline TC $(\mathrm{mmol} / \mathrm{l})$ & $4 \cdot 71$ & 0.93 & $4 \cdot 81$ & $1 \cdot 08$ \\
\hline HDL-C (mmol/l) & $1 \cdot 00$ & 0.25 & $1 \cdot 22$ & $0 \cdot 31$ \\
\hline LDL-C (mmol/l) & $2 \cdot 91$ & $0 \cdot 81$ & $2 \cdot 95$ & 0.92 \\
\hline TAG $(\mathrm{mmol} / \mathrm{l}) \dagger$ & $1 \cdot 47$ & $1 \cdot 04,2 \cdot 13$ & $1 \cdot 21$ & $0.88,1.68$ \\
\hline
\end{tabular}
of $0.500(P<0 \cdot 01)$, the area under the line of no discrimination. In women, the relationship between WHtR and dyslipidemia seems to be weaker. Cut-off points with

Table 2 Clinical characteristics of the study sample: Turkish men and women aged 18 years and over, 2003

WC, waist circumference; WHpR, waist:hip ratio; WHtR, waist:height ratio; SBP, systolic blood pressure; DBP, diastolic blood pressure; HOMA-IR, homeostasis model assessment of insulin resistance; TC, total cholesterol; HDL-C, HDL cholesterol; LDL-C, LDL cholesterol.

Summarized from Table 1 of our previous publication ${ }^{(19)}$.

Results are presented as arithmetic mean and standard deviation, or as tmedian and 25 th, 75 th percentile for continuous variables with a positively skewed distribution. 
the highest Youden index are presented in Table 5. The sensitivities of the identified cut-off points for detecting cardiometabolic risk factors are between 0.72 and 0.81 in

Table 3 The frequency of cardiometabolic risk factors, diabetes and CHD in the study sample: Turkish men and women aged 18 years and over, 2003

\begin{tabular}{lrrrrrrr}
\hline & \multicolumn{3}{c}{ Men $(n 571)$} & & \multicolumn{3}{c}{ Women $(n 1121)$} \\
\cline { 2 - 3 } \cline { 7 - 8 } Risk factor & $n$ & $\%$ & $95 \% \mathrm{Cl}$ & & $n$ & $\%$ & $95 \% \mathrm{Cl}$ \\
\hline Hypertension & 254 & 45 & 41,49 & & 518 & 46 & 43,49 \\
Diabetes & 40 & 7 & 5,9 & & 79 & 7 & 6,8 \\
Dyslipidaemia & 383 & 67 & 63,71 & & 478 & 43 & 40,46 \\
Metabolic syndrome & 250 & 44 & 40,48 & & 525 & 47 & 44,50 \\
MSS $\geq 2$ & 332 & 58 & 54,62 & & 598 & 53 & 50,56 \\
ALORF & 469 & 82 & 79,85 & & 726 & 65 & 62,68 \\
CHD & 36 & 6 & 4,8 & & 75 & 7 & 6,8 \\
\hline
\end{tabular}

Metabolic syndrome, subjects with three or more abnormal modified US National Cholesterol Education Program (NCEP)-defined metabolic syndrome components ${ }^{(1,23)}$; MSS $\geq 2$, subjects with two or more abnorma modified NCEP-defined metabolic syndrome components excluding wais circumference; ALORF, at least one risk factor (hypertension, diabetes or dyslipidaemia) is present; CHD, self-reported CHD history.

Summarized from Table 1 of our previous publication ${ }^{(19)}$.

Table 4 Area under the receiver-operating characteristic curves (AUC) and $95 \%$ confidence intervals of waist:height ratio for cardiometabolic risk factors: Turkish men and women aged 18 years and over, 2003

\begin{tabular}{lccccc}
\hline & \multicolumn{2}{c}{ Women $(n 1121)$} & & \multicolumn{2}{c}{ Men $(n$ 571) } \\
\cline { 2 - 3 } \cline { 6 - 7 } Risk factor & AUC & $95 \% \mathrm{Cl}$ & & AUC & $95 \% \mathrm{Cl}$ \\
\hline Hypertension & 0.776 & $0.749,0.803$ & & 0.686 & $0.642,0.730$ \\
Dyslipidaemia & 0.630 & $0.598,0.662$ & & 0.608 & $0.558,0.657$ \\
Diabetes & 0.732 & $0.684,0.780$ & & 0.606 & $0.515,0.696$ \\
MSS $\geq 2$ & 0.763 & $0.735,0.791$ & & 0.697 & $0.653,0.740$ \\
ALORF & 0.757 & $0.727,0.787$ & & 0.693 & $0.637,0.748$ \\
\hline
\end{tabular}

MSS $\geq 2$, subjects with two or more abnormal modified US National Cholesterol Education Program-defined metabolic syndrome components excluding waist circumference ${ }^{(1,23)}$; ALORF, at least one risk factor (hypertension, dyslipidaemia or diabetes) is present.

Summarized from our previous publication ${ }^{(19)}$.

All areas under the receiver-operating characteristic curves are significantly different from 0.500 , the value that indicates the area under the line of no discrimination $(P<0 \cdot 05)$. women and between 0.63 and 0.70 in men. The specificities of the identified cut-off points range between 0.42 and 0.71 in women and between 0.48 and 0.67 in men. The accuracies of the cut-offs to discriminate diabetes and dyslipidaemia are lower. The accuracies of the cut-offs for hypertension, MSS $\geq 2$ and ALORF range between 0.65 and $0 \cdot 73$, in men and women. Table 5 shows that the best cut-off point is between 0.56 and $0 \cdot 60$. Cut-off values for cardiometabolic risk factors are almost equal between men and women. The cut-off of 0.59 is the most frequently identified value in Table 5 .

In the next step, subjects were grouped according to age tertiles and the same analyses were repeated. Table 6 shows that the AUC for diabetes in women $\leq 38$ years old, the AUC for dyslipidaemia in women $\geq 51$ years old and the AUC for diabetes in men are not different from the chance line (AUC $=0 \cdot 500$ ), meaning that WHtR has no discriminatory capability for dyslipidaemia and diabetes in these groups. Table 7 shows optimal WHtR cut-off points for cardiometabolic risk factors by gender and age tertile. Optimal WHtR cut-offs range between 0.50 and $0 \cdot 67$. The sensitivities of the identified optimal cut-offs range between $0 \cdot 40$ and $0 \cdot 91$, specificities between $0 \cdot 31$ and 0.89 and accuracies between 0.46 and 0.78 . The optimal WHtR cut-off seems to increase as age advances. As in Table 5, 0.59 is also the most frequent cut-off value in Table 7 . When the prevalence of the studied cardiometabolic risk factor is low, as in diabetes, the PPV of the cut-off is low and the NPV is high. When the prevalence is high, as in ALORF, the PPV is high and the NPV is low (Table 7). If diabetes and ALORF are omitted from Table 7, PPV ranges between 0.32 and $0 \cdot 88$ and NPV ranges between 0.35 and 0.93 . The scientific conclusion from Tables 5 and 7 is to employ different optimal cut-off values for different cardiometabolic risk factors that vary by age tertile and gender. However, as 0.59 is the most frequent number in Tables 5 and 7 , it was pragmatically selected as the optimal cut-off point for discrimination of cardiometabolic risk factors.

Table 5 Optimal waist:height ratio cut-offs for cardiometabolic risk factors and the sensitivity, specificity, positive predictive value (PPV), negative predictive value (NPV) and accuracy of the cut-offs: Turkish men and women aged 18 years and over, 2003

\begin{tabular}{|c|c|c|c|c|c|c|}
\hline & Cut-offt & Sensitivity & Specificity & PPV & NPV & Accuracy \\
\hline \multicolumn{7}{|l|}{ Women (n 1121) } \\
\hline Hypertension & $0 \cdot 60$ & $0 \cdot 72$ & $0 \cdot 71$ & 0.68 & 0.75 & $0 \cdot 71$ \\
\hline Dyslipidaemia & 0.56 & 0.79 & 0.42 & 0.51 & 0.73 & 0.58 \\
\hline Diabetes & 0.60 & 0.81 & 0.53 & 0.11 & 0.97 & 0.55 \\
\hline$M S S \geq 2$ & 0.58 & $0 \cdot 78$ & 0.65 & 0.72 & 0.72 & 0.72 \\
\hline ALORF & 0.56 & $0 \cdot 81$ & 0.59 & 0.79 & 0.63 & 0.73 \\
\hline \multicolumn{7}{|l|}{ Men $(n$ 571) } \\
\hline Hypertension & 0.59 & 0.68 & 0.63 & 0.60 & 0.71 & 0.65 \\
\hline Dyslipidaemia & 0.57 & 0.69 & 0.48 & 0.73 & 0.43 & 0.62 \\
\hline Diabetes & 0.59 & $0 \cdot 70$ & 0.51 & $0 \cdot 10$ & 0.96 & 0.52 \\
\hline$M S S \geq 2$ & 0.59 & 0.63 & 0.67 & 0.73 & 0.57 & 0.65 \\
\hline ALORF & 0.57 & 0.69 & 0.63 & 0.89 & 0.31 & 0.68 \\
\hline
\end{tabular}

MSS $\geq 2$, subjects with two or more abnormal modified US National Cholesterol Education Program-defined metabolic syndrome components excluding waist circumference ${ }^{(1,23)}$; ALORF, at least one risk factor (hypertension, dyslipidaemia or diabetes) is present. tOptimal cut-off is identified as the value that has the highest Youden index, $J: J=$ sensitivity + specificity -1 . 
Table 6 Area under the receiver-operating characteristic curves (AUC) and 95\% confidence intervals of waist:height ratio for cardiometabolic risk factors by age tertile and gender: Turkish men and women aged 18 years and over, 2003

\begin{tabular}{|c|c|c|c|c|c|c|}
\hline \multirow[b]{2}{*}{ Risk factor } & \multicolumn{2}{|c|}{ Age $\leq 38$ years } & \multicolumn{2}{|c|}{ Age $39-50$ years } & \multicolumn{2}{|c|}{ Age $\geq 51$ years } \\
\hline & AUC & $95 \% \mathrm{Cl}$ & AUC & $95 \% \mathrm{Cl}$ & AUC & $95 \% \mathrm{Cl}$ \\
\hline Women & \multicolumn{2}{|c|}{ (n 342) } & \multicolumn{2}{|c|}{$(n 400)$} & \multicolumn{2}{|c|}{$(n 379)$} \\
\hline Hypertension & 0.777 & $0.715,0.838$ & 0.717 & $0.668,0.767$ & 0.703 & $0.643,0.763$ \\
\hline Dyslipidaemia & 0.681 & $0.624,0.738$ & $0 \cdot 641$ & $0 \cdot 588,0695$ & $0.539^{\star}$ & $0.481,0.597$ \\
\hline Diabetes & $0.605^{\star}$ & $0.000,1.000$ & 0.718 & $0.621,0.814$ & $0 \cdot 618$ & $0.543,0.694$ \\
\hline$M S S \geq 2$ & $0 \cdot 765$ & $0.710,0.820$ & 0.734 & $0.683,0.784$ & 0.657 & $0.597,0.717$ \\
\hline ALORF & 0.726 & $0.673,0.779$ & 0.712 & $0.659,0.765$ & 0.672 & $0.597,0.747$ \\
\hline Men & \multicolumn{2}{|c|}{$(n$ 195) } & \multicolumn{2}{|c|}{$(n$ 191) } & \multicolumn{2}{|c|}{$(n$ 185) } \\
\hline Hypertension & 0.673 & $0.587,0.759$ & 0.665 & $0.587,0.743$ & 0.654 & $0.568,0.741$ \\
\hline Dyslipidaemia & 0.597 & $0.514,0.680$ & 0.622 & $0.532,0.711$ & 0.598 & $0.512,0.683$ \\
\hline Diabetes & $0.567^{\star}$ & $0.291,0.844$ & $0.610^{*}$ & $0.447,0.773$ & $0.545^{\star}$ & $0.418,0.672$ \\
\hline$M S S \geq 2$ & 0.673 & $0.597,0.749$ & 0.705 & $0.627,0.783$ & 0.674 & $0.595,0.753$ \\
\hline ALORF & 0.640 & $0.556,0.724$ & 0.696 & $0.596,0.796$ & 0.663 & $0.514,0.813$ \\
\hline
\end{tabular}

MSS $\geq 2$, subjects with two or more abnormal modified US National Cholesterol Education Program-defined metabolic syndrome components excluding waist circumference $^{(1,23)}$; ALORF, at least one risk factor (hypertension, dyslipidaemia or diabetes) is present.

${ }^{*} P>0.05$ compared with 0.500 ; unmarked areas under the receiver-operating characteristic curves are significantly different from 0.500 , the value that indicates the area under the line of no discrimination $(P<0.05)$.

Table 7 The prevalence of cardiometabolic risk factors, optimal waist:height ratio (WHtR) cut-offs and the sensitivity, specificity, positive predictive value (PPV), negative predictive value (NPV) and accuracy of the cut-offs by age tertile and gender: Turkish men and women aged 18 years and over, 2003

\begin{tabular}{|c|c|c|c|c|c|c|c|}
\hline & Prevalence & Cut-offt & Sensitivity & Specificity & PPV & NPV & Accuracy \\
\hline \multicolumn{8}{|c|}{ Women, age $\leq 38$ years $(n 342)$} \\
\hline Hypertension & $0 \cdot 16$ & 0.57 & 0.72 & $0 \cdot 71$ & 0.32 & 0.93 & $0 \cdot 71$ \\
\hline Dyslipidaemia & 0.35 & 0.50 & 0.91 & $0 \cdot 39$ & 0.45 & $0 \cdot 89$ & 0.57 \\
\hline Diabetes & 0.01 & NA & NA & NA & NA & NA & NA \\
\hline$M S S \geq 2$ & $0 \cdot 30$ & 0.56 & $0 \cdot 70$ & 0.73 & 0.53 & 0.85 & $0 \cdot 72$ \\
\hline ALORF & 0.42 & 0.55 & 0.64 & $0 \cdot 70$ & $0 \cdot 61$ & $0 \cdot 73$ & 0.67 \\
\hline \multicolumn{8}{|c|}{ Women, age $39-50$ years ( $n$ 400) } \\
\hline Hypertension & 0.44 & 0.58 & 0.77 & 0.55 & 0.57 & $0 \cdot 75$ & 0.65 \\
\hline Dyslipidaemia & 0.42 & 0.58 & 0.72 & 0.50 & 0.51 & $0 \cdot 71$ & 0.59 \\
\hline Diabetes & 0.05 & 0.61 & 0.79 & 0.59 & 0.09 & 0.98 & 0.60 \\
\hline MSS $\geq 2$ & 0.57 & 0.58 & 0.75 & 0.62 & 0.72 & 0.65 & 0.69 \\
\hline ALORF & 0.63 & 0.55 & 0.88 & 0.44 & 0.73 & 0.68 & $0 \cdot 72$ \\
\hline \multicolumn{8}{|c|}{ Women, age $\geq 51$ years $(n 379)$} \\
\hline Hypertension & $0 \cdot 77$ & 0.63 & 0.59 & $0 \cdot 73$ & $0 \cdot 88$ & $0 \cdot 35$ & 0.62 \\
\hline Dyslipidaemia & 0.50 & NA & NA & NA & NA & NA & NA \\
\hline Diabetes & $0 \cdot 15$ & 0.65 & 0.64 & $0 \cdot 60$ & 0.22 & 0.90 & $0 \cdot 61$ \\
\hline$M S S \geq 2$ & $0 \cdot 71$ & 0.59 & 0.83 & $0 \cdot 40$ & $0 . \overline{77}$ & 0.49 & $0 \cdot 71$ \\
\hline ALORF & 0.88 & 0.67 & 0.40 & 0.89 & 0.96 & $0 \cdot 17$ & $0 \cdot 46$ \\
\hline \multicolumn{8}{|c|}{ Men, age $\leq 38$ years $(n 195)$} \\
\hline Hypertension & 0.26 & 0.59 & 0.54 & $0 \cdot 72$ & $0 \cdot 40$ & $0 \cdot 82$ & $0 \cdot 67$ \\
\hline Dyslipidaemia & 0.64 & 0.57 & 0.53 & 0.67 & 0.74 & 0.45 & 0.58 \\
\hline Diabetes & 0.03 & NA & NA & NA & NA & NA & NA \\
\hline$M S S \geq 2$ & 0.47 & 0.57 & 0.63 & $0 \cdot 69$ & 0.64 & 0.68 & 0.66 \\
\hline ALORF & 0.73 & 0.57 & 0.53 & $0 \cdot 74$ & 0.85 & 0.37 & 0.59 \\
\hline \multicolumn{8}{|c|}{ Men, age $39-50$ years $(n 191)$} \\
\hline Hypertension & 0.41 & 0.61 & 0.56 & 0.72 & 0.58 & 0.70 & 0.65 \\
\hline Dyslipidaemia & 0.73 & 0.55 & 0.89 & $0 \cdot 31$ & 0.78 & 0.51 & 0.73 \\
\hline Diabetes & 0.07 & NA & NA & NA & NA & NA & NA \\
\hline$M S S \geq 2$ & 0.67 & 0.59 & 0.65 & $0 \cdot 67$ & 0.80 & 0.49 & 0.66 \\
\hline ALORF & 0.83 & 0.59 & 0.60 & $0 \cdot 70$ & 0.91 & 0.26 & 0.62 \\
\hline \multicolumn{8}{|c|}{ Men, age $\geq 51$ years $(n 185)$} \\
\hline Hypertension & 0.68 & 0.60 & 0.66 & 0.65 & 0.80 & 0.47 & 0.66 \\
\hline Dyslipidaemia & 0.64 & 0.59 & 0.71 & 0.49 & $0 \cdot 71$ & 0.49 & $0 \cdot 63$ \\
\hline Diabetes & $0 \cdot 11$ & NA & NA & NA & NA & NA & NA \\
\hline MSS $\geq 2$ & 0.61 & 0.60 & 0.67 & 0.63 & 0.74 & 0.55 & 0.65 \\
\hline ALORF & 0.91 & 0.56 & 0.81 & 0.50 & 0.94 & 0.21 & 0.78 \\
\hline
\end{tabular}

MSS $\geq 2$, subjects with two or more abnormal modified US National Cholesterol Education Program-defined metabolic syndrome components excluding waist circumference ${ }^{(1,23)}$; ALORF, at least one risk factor (hypertension, dyslipidaemia or diabetes) is present; NA, not applicable because the area under the receiver-operating characteristic curve of $\mathrm{WHtR}$ is not significantly different from 0.500 , the area under the line of no discrimination (see Table 6 ).

tOptimal cut-off is identified as the value that has the highest Youden index, $J: J=$ sensitivity + specificity -1 . 
Table 8 Odds ratios and $95 \%$ confidence intervals for cardiometabolic risk factors in subjects classified as having waist:height ratio $(\mathrm{WHtR}) \geq 0.59+v$. subjects with $\mathrm{WHtR}<0.59$ (where OR $=1.00$ ) after controlling for age, rural $v$. urban residence, smoking, alcohol consumption, physical activity, income and education level: Turkish men and women aged 18 years and over, 2003

\begin{tabular}{|c|c|c|c|c|}
\hline \multirow[b]{2}{*}{ Risk factor } & \multicolumn{2}{|c|}{ Women } & \multicolumn{2}{|c|}{ Men } \\
\hline & OR & $95 \% \mathrm{Cl}$ & OR & $95 \% \mathrm{Cl}$ \\
\hline Hypertension & $3 \cdot 00$ & $2 \cdot 22,4 \cdot 07$ & 3.09 & $2 \cdot 08,4 \cdot 61$ \\
\hline Dyslipidaemia & $1 \cdot 70$ & $1 \cdot 29,2 \cdot 24$ & $2 \cdot 03$ & $1 \cdot 37,3 \cdot 01$ \\
\hline Diabetes & $2 \cdot 21$ & $1 \cdot 16,4 \cdot 21$ & $1 \cdot 91$ & $0.93,3.92$ \\
\hline$M S S \geq 2$ & $3 \cdot 66$ & $2 \cdot 75,4 \cdot 86$ & $3 \cdot 87$ & $2 \cdot 62,5 \cdot 72$ \\
\hline ALORF & $2 \cdot 50$ & $1 \cdot 84,3 \cdot 39$ & $2 \cdot 94$ & $1.73,4.99$ \\
\hline
\end{tabular}

MSS $\geq 2$, subjects with two or more abnormal modified US National Cholesterol Education Program-defined metabolic syndrome components excluding waist circumference ${ }^{(1,23)}$; ALORF, at least one risk factor (hypertension, dyslipidaemia or diabetes) is present.

tFifty-one per cent of women and $47 \%$ of men had $\mathrm{WHtR} \geq 0.59$.

The AUC of WHtR for self-reported history of CHD was $0.606(95 \%$ CI $0.540,0.672)$ in women. WHtR was not a significant discriminator of CHD in men. The optimal cutoff value of WHtR for CHD was 0.62 in women. When ROC curves for CHD were constructed by age tertile, the AUC was significant only in women in the age group of $\geq 51$ years. The AUC of WHtR for CHD in women in the age group $\geq 51$ years was 0.609 (95\% CI $0.530,0 \cdot 689$ ). The prevalence of CHD was $13 \%$ and the optimal cut-off value of WHtR for CHD was 0.63 in women who were $\geq 51$ years of age.

Forty-seven per cent of men ( $n$ 266) and $51 \%$ of women ( $n$ 575) had WHtR $\geq 0.59$. The age- and sociodemographic variable-controlled odds ratios of subjects with WHtR $\geq 0.59$ for hypertension, dyslipidaemia, diabetes, MSS $\geq 2$ and ALORF were calculated by logistic regression $v$. those with $\mathrm{WHtR}<0.59$ (Table 8). The status of having WHtR $\geq 0.59$ significantly increased the risk of having cardiometabolic risk factors, except for diabetes in men. Age, rural $v$. urban residence, smoking and alcohol consumption were also significant contributors to the studied cardiometabolic risk factors.

\section{Discussion}

Ashwell and Hsieh suggested global use of WHtR as a rapid screening tool for cardiometabolic risk factors with this simple public health message ${ }^{(28)}$ : 'Keep your waist circumference to less than half your height'. In the following, the first sentence is from Ashwell and Hsieh's arguments to defend the superiority of WHtR over other anthropometric indices and the second sentence reflects our opinion based on our data or literature review.

1. WHtR is more sensitive than BMI as an early warning of health risks. We confirmed previously that WHtR is the best anthropometric index for discriminating cardiometabolic risk factors in Turkish adults ${ }^{(19)}$.
2. WHtR is cheaper and easier to measure and calculate than BMI. A measuring tape is cheaper than a scale and there is a need to square the height as when calculating BMI, therefore this statement is true.

3. A cut-off point of $\mathrm{WHtR}=0.50$ indicates increased risk for men and women. We agree with the second part of this statement; based on our data, cut-off values of WHtR are close in men and women.

4. A cut-off point of $\mathrm{WHtR}=0.50$ indicates increased risk for people in different ethnic groups. We disagree; our data show that the cut-off value of 0.59 is optimal in Turkish men and women.

Although WHtR seems the best anthropometric index for discrimination of cardiometabolic risk factors, there is a disparity in the optimal cut-off points between ethnic groups. In a recent meta-analysis, Lee and co-workers discussed the utility of universal $v$. ethnic-specific WHtR cut-off points and found that the optimal WHtR cut-off ranged from 0.46 to 0.62 in studies from different countries $^{(10)}$. Our findings are in favour of ethnic-specific cutoffs. Although a WHtR cut-off of $\geq 0.50$ is the best for Eastern Asia ${ }^{(13,29-31)}$, a cross-sectional study reported that the optimal WHtR cut-off value is between 0.54 and 0.59 in Germany ${ }^{(14)}$. From a cross-sectional study in Iran, Mirmiran and co-workers reported that the optimal WHtR cut-off should be between 0.47 and 0.56 for men, and between 0.50 and 0.63 for women ${ }^{(32)}$. From a crosssectional study in Iraq, Mansour and Al-Jazairi reported a WHtR cut-off value of 0.55 for men and 0.59 for women for discrimination of hypertension ${ }^{(33)}$. Except for the studies of Aekplakorn et $a l^{(29)}$, Fuchs et al. ${ }^{(18)}$, Hadaegh et $a l^{(34)}$ and Gelber et $a l^{(35)}$, all studies that suggest the superiority of WHtR are cross-sectional ${ }^{(11-17,30-33)}$. Crosssectional design and risk factors as dependent variables are major limitations of those studies, as is the case with our study. A prospective cohort study with 17 years of follow-up found WHtR as the best predictor of future CHD in Thai men who were 35 to 59 years of age at baseline ${ }^{(29)}$. A prospective study from Iraq reported the WHtR cut-off to predict incident diabetes as 0.52 for males and 0.57 for females ${ }^{(36)}$. Of note, WHpR, not WHtR showed the strongest association with incident diabetes in that study. More prospective studies with clinical end points are needed to establish the superiority of WHtR as an anthropometric index and the validity of our and others' suggested cut-off points.

We have previously shown that WC, WHpR, BMI and HC are worse than WHtR in discriminating cardiometabolic risk factors ${ }^{(19)}$. The vast majority of AUC in Tables 4 and 6 are significantly different from the AUC value of $0 \cdot 50$, indicating that using anthropometric indices is better than chance to guess the presence or absence of cardiometabolic risk factors in a patient. The AUC in Tables 4 and 6 are not very close to the AUC value of $1 \cdot 00$, meaning that anthropometric indices are not perfect 
discriminators of cardiometabolic risk factors and nevertheless cannot replace the clinical and laboratory evaluation of cardiometabolic risk factors.

An easy-to-remember cut-off value is an advantage for both health-care professionals and lay people. In our opinion, there is no question that individuals should be able to achieve self-diagnosis by using the globally - or at least nationally - applicable anthropometric index and its cut-off point. A WHtR cut-off point of $\geq 0.50$ as action level one, and $\geq 0 \cdot 60$ as action level two, have been suggested $^{(10)}$. Eighty-eight per cent of our sample had WHtR $\geq 0.50,50 \%$ had WHtR $\geq 0.59$ and $45 \%$ had $\mathrm{WHtR} \geq 0 \cdot 60$. For both men and women, the sensitivities of the WHtR $\geq 0.50$ cut-off for cardiometabolic risk factors were over $0 \cdot 94$, but the specificities ranged between 0.07 and 0.29 and the accuracies between 0.13 and 0.79 (data not shown). As the specificities, PPV and accuracies of the WHtR $\geq 0.50$ cut-off for cardiometabolic risk factors are worse than those of the WHtR $\geq 0.59$ cut-off, we think that categorizing cut-off values as action level one and two for action and alarm has the potential for error and miscommunication. A single WHtR cut-off value could be more easily adopted and remembered by health-care professionals, media and the public.

\section{Conclusions}

We have previously identified WHtR as the best anthropometric index to screen for cardiometabolic risk factors in Turkish adults ${ }^{(19)}$. In the current report, we show that the optimal WHtR cut-off point to predict cardiometabolic risk factors is 0.59 , for both Turkish men and women.

\section{Acknowledgements}

Sources of funding: All authors were funded by their institutions. The cost of the laboratory work was supported by the Gladstone Institute of Cardiovascular Disease. Conflict of interest: The authors declare that they have no conflict of interest. Authors' contributions: A.S.C. contributed to data acquisition, data evaluation and statistical analysis, and wrote the manuscript. E.A.Y., G.S., N.R., G.P., S.Ö. and T.B.P. contributed to data acquisition. K.E.P. measured laboratory variables. M.G. contributed to statistical analysis. G.P. and T.B.P. obtained approval from the Central Ethics Committee of Turkish Ministry of Health. Acknowledgements: We thank to Miss Sibel Tanır and Mr Guy Pepin from the Istanbul Office of Gladstone Institute of Cardiovascular Disease for helping in subject recruitment, blood drawing and data collection.

\section{References}

1. Expert Panel on Detection, Evaluation, and Treatment of High Blood Cholesterol in Adults (2001) Executive
Summary of The Third Report of The National Cholesterol Education Program (NCEP) Expert Panel on Detection, Evaluation, And Treatment of High Blood Cholesterol In Adults (Adult Treatment Panel III). JAMA 285, 2486-2497.

2. Malik S, Wong ND, Franklin SS, Kamath TV, L'Italien GJ, Pio JR \& Williams GR (2004) Impact of the metabolic syndrome on mortality from coronary heart disease, cardiovascular disease, and all causes in United States adults. Circulation 110, 1245-1250.

3. Guize L, Thomas F, Pannier B, Bean K, Jego B \& Benetos A (2007) All-cause mortality associated with specific combinations of the metabolic syndrome according to recent definitions. Diabetes Care 30, 2381-2387.

4. Lorenzo C, Williams K, Hunt KJ \& Haffner SM (2007) The National Cholesterol Education Program - Adult Treatment Panel III, International Diabetes Federation, and World Health Organization definitions of the metabolic syndrome as predictors of incident cardiovascular disease and diabetes. Diabetes Care 30, 8-13.

5. Gami AS, Witt BJ, Howard DE, Erwin PJ, Gami LA, Somers VK \& Montori VM (2007) Metabolic syndrome and risk of incident cardiovascular events and death: a systematic review and meta-analysis of longitudinal studies. $\mathrm{J} \mathrm{Am} \mathrm{Coll}$ Cardiol 49, 403-414.

6. Pischon T, Boeing H, Hoffmann K et al. (2008) General and abdominal adiposity and risk of death in Europe. $N$ Engl J Med 359, 2105-2120.

7. Schooling CM, Thomas GN, Leung GM, Ho SY, Janus ED \& Lam TH (2007) Is height associated with cardiovascular risk in Chinese adults? Epidemiology 18, 274-278.

8. McCarron P, Okasha M, McEwen J \& Smith GD (2002) Height in young adulthood and risk of death from cardiorespiratory disease: a prospective study of male former students of Glasgow University, Scotland. Am J Epidemiol 155, 683-687.

9. Engeland A, Bjorge T, Selmer RM \& Tverdal A (2003) Height and body mass index in relation to total mortality. Epidemiology 14, 293-299.

10. Lee CM, Huxley RR, Wildman RP \& Woodward M (2008) Indices of abdominal obesity are better discriminators of cardiovascular risk factors than BMI: a meta-analysis. J Clin Epidemiol 61, 646-653.

11. Aekplakorn W, Kosulwat V \& Suriyawongpaisal P (2006) Obesity indices and cardiovascular risk factors in Thai adults. Int J Obes (Lond) 30, 1782-1790.

12. Hsieh SD \& Muto T (2005) The superiority of waist-toheight ratio as an anthropometric index to evaluate clustering of coronary risk factors among non-obese men and women. Prev Med 40, 216-220.

13. Hsieh SD \& Muto T (2006) Metabolic syndrome in Japanese men and women with special reference to the anthropometric criteria for the assessment of obesity: proposal to use the waist-to-height ratio. Prev Med 42, 135-139.

14. Schneider HJ, Glaesmer H, Klotsche J, Bohler S, Lehnert H, Zeiher AM, Marz W, Pittrow D, Stalla GK \& Wittchen HU (2007) Accuracy of anthropometric indicators of obesity to predict cardiovascular risk. J Clin Endocrinol Metab 92, 589-594.

15. Ashwell M \& Gibson S (2009) Waist to height ratio is a simple and effective obesity screening tool for cardiovascular risk factors: analysis of data from the British National Diet and Nutrition Survey of adults aged 19-64 years. Obesity Facts 2, 97-103.

16. Lin WY, Lee LT, Chen CY, Lo H, Hsia HH, Liu IL, Lin RS, Shau WY \& Huang KC (2002) Optimal cut-off values for obesity: using simple anthropometric indices to predict cardiovascular risk factors in Taiwan. Int J Obes Relat Metab Disord 26, 1232-1238.

17. Sayeed MA, Mahtab H, Latif ZA, Khanam PA, Ahsan KA, Banu A \& Azad Khan AK (2003) Waist-to-height ratio is a 
better obesity index than body mass index and waist-to-hip ratio for predicting diabetes, hypertension and lipidemia. Bangladesh Med Res Counc Bull 29, 1-10.

18. Fuchs FD, Gus M, Moreira LB, Moraes RS, Wiehe M, Pereira GM \& Fuchs SC (2005) Anthropometric indices and the incidence of hypertension: a comparative analysis. Obes Res 13, 1515-1517.

19. Can AS, Bersot TP \& Gonen M (2009) Anthropometric indices and their relationship with cardiometabolic risk factors in a sample of Turkish adults. Public Health Nutr 12, 538-546.

20. Matthews DR, Hosker JP, Rudenski AS, Naylor BA, Treacher DF \& Turner RC (1985) Homeostasis model assessment: insulin resistance and $\beta$-cell function from fasting plasma glucose and insulin concentrations in man. Diabetologia 28, 412-419.

21. Chobanian AV, Bakris GL, Black HR et al. (2003) The Seventh Report of the Joint National Committee on Prevention, Detection, Evaluation, and Treatment of High Blood Pressure: the JNC 7 report. JAMA 289, 2560-2572.

22. Expert Committee on the Diagnosis and Classification of Diabetes Mellitus (2003) Report of the expert committee on the diagnosis and classification of diabetes mellitus. Diabetes Care 26, Suppl. 1, S5-S20.

23. Grundy SM, Cleeman JI, Daniels SR et al. (2005) Diagnosis and management of the metabolic syndrome: an American Heart Association/National Heart, Lung, and Blood Institute Scientific Statement. Circulation 112, 2735-2752.

24. DeLong ER, DeLong DM \& Clarke-Pearson DL (1988) Comparing the areas under two or more correlated receiver operating characteristic curves: a nonparametric approach. Biometrics 44, 837-845.

25. Youden WJ (1950) Index for rating diagnostic tests. Cancer 3, 32-35.

26. Perkins NJ \& Schisterman EF (2006) The inconsistency of 'optimal' cutpoints obtained using two criteria based on the receiver operating characteristic curve. Am J Epidemiol 163, 670-675.
27. Pepe M (2003) The Statistical Evaluation of Medical Tests for Classification and Prediction. New York: Oxford University Press.

28. Ashwell M \& Hsieh SD (2005) Six reasons why the waist-toheight ratio is a rapid and effective global indicator for health risks of obesity and how its use could simplify the international public health message on obesity. Int J Food Sci Nutr 56, 303-307.

29. Aekplakorn W, Pakpeankitwatana V, Lee CM, Woodward M, Barzi F, Yamwong S, Unkurapinun N \& Sritara P (2007) Abdominal obesity and coronary heart disease in Thai men. Obesity (Silver Spring) 15, 1036-1042.

30. Shimajiri $T$, Imagawa $M$, Kokawa $M$, Konami $T$, Hara $H$, Kyoku I, Sone E, Ishigame M \& Kikuoka H (2008) Revised optimal cut-off point of waist circumference for the diagnosis of metabolic syndrome in Japanese women and the influence of height. J Atheroscler Thromb 15, 94-99.

31. Wu HY, Chen LL, Zheng J, Liao YF \& Zhou M (2007) Simple anthropometric indices in relation to cardiovascular risk factors in Chinese type 2 diabetic patients. Chin J Physiol 50, 135-142.

32. Mirmiran P, Esmaillzadeh A \& Azizi F (2004) Detection of cardiovascular risk factors by anthropometric measures in Tehranian adults: receiver operating characteristic (ROC) curve analysis. Eur J Clin Nutr 58, 1110-1118.

33. Mansour AA \& Al-Jazairi MI (2007) Cut-off values for anthropometric variables that confer increased risk of type 2 diabetes mellitus and hypertension in Iraq. Arch Med Res 38, 253-258.

34. Hadaegh F, Zabetian A, Harati H \& Azizi F (2006) Waist/ height ratio as a better predictor of type 2 diabetes compared to body mass index in Tehranian adult men a 3.6-year prospective study. Exp Clin Endocrinol Diabetes 114, 310-315.

35. Gelber RP, Gaziano JM, Orav EJ, Manson JE, Buring JE \& Kurth T (2008) Measures of obesity and cardiovascular risk among men and women. J Am Coll Cardiol 52, 605-615.

36. Mansour AA \& Al-Jazairi MI (2007) Predictors of incident diabetes mellitus in Basrah, Iraq. Ann Nutr Metab 51, 277-280. 